\title{
PERFORMANCE ANALYSIS OF LOW-COST SINGLE-FREQUENCY GPS RECEIVERS IN HYDROGRAPHIC SURVEYING
}

\author{
Mohamed Elsobeiey \\ Department of Hydrographic Surveying, Faculty of Maritime Studies, King Abdulaziz University \\ P. O. Box 20807 - Jeddah 21589, Kingdom of Saudi Arabia \\ melsobeiey@kau.edu.sa
}

KEY WORDS: Hydrographic Surveying; Single-Frequency; IHO; Precise Point Positioning

\begin{abstract}
:
The International Hydrographic Organization (IHO) has issued standards that provide the minimum requirements for different types of hydrographic surveys execution to collect data to be used to compile navigational charts. Such standards are usually updated from time to time to reflect new survey techniques and practices and must be achieved to assure both surface navigation safety and marine environment protection. Hydrographic surveys can be classified to four orders namely, special order, order 1a, order $1 \mathrm{~b}$, and order2. The order of hydrographic surveys to use should be determined in accordance with the importance to the safety of navigation in the surveyed area. Typically, geodetic-grade dual-frequency GPS receivers are utilized for position determination during data collection in hydrographic surveys. However, with the evolution of high-sensitivity low-cost single-frequency receivers, it is very important to evaluate the performance of such receivers. This paper investigates the performance of low-cost single-frequency GPS receivers in hydrographic surveying applications. The main objective is to examine whether low-cost single-frequency receivers fulfil the IHO standards for hydrographic surveys. It is shown that the low-cost single-frequency receivers meet the IHO horizontal accuracy for all hydrographic surveys orders at any depth. However, the single-frequency receivers meet only order 2 requirements for vertical accuracy at depth more than or equal $100 \mathrm{~m}$.
\end{abstract}

\section{INTRODUCTION}

Typically, commercial GPS receivers vary according to their receiving capabilities. There are different types such as singlefrequency code receivers, single-frequency carrier-smoothed code receivers, single-frequency code and carrier receivers, dual-frequency receivers, and triple-frequency receivers. Singlefrequency receivers access the L1 frequency only. Dualfrequency receivers access both the L1 and the L2 frequencies, while triple-frequency receivers access L1, L2, and L5 frequencies.

The first type of single-frequency GPS receivers, the singlefrequency code receiver, is the cheapest and the least accurate type of receivers. It measures the pseudoranges with the C/Acode only. The second receiver type, the single-frequency carrier-smoothed code receiver, uses the L1 carrier phase to produce high-precision C/A-code measurements. Singlefrequency code and carrier receivers output the raw C/A-code pseudoranges, the $\mathrm{L} 1$ carrier phase measurements in addition to the navigation message. Dual-frequency receivers are the most sophisticated and most expensive receiver type. They measure GPS data on both L1 and L2 frequencies. Triple-frequency receivers, on the other hand, are able to produce measurements on the legacy frequencies L1 and L2 and the modernized frequency L5.

Unlike dual-frequency receivers, however, ionosphere delay represents a major challenge for single-frequency receivers.
There are two main approaches to correct single-frequency data from the ionosphere delay (Cai et al., 2013). The first technique is to use ionosphere models to correct for the ionosphere delay. These models may be empirical models such as Klobuchar model, which can account for up to $60 \%$ of the delay at midlatitudes (El-Rabbany, 2006). Klobuchar model coefficients are transmitted as part of the navigation message and can be improved by extending the eight parameters original Klobuchar model to ten-parameters to account for the ionosphere variation during the night time (Wang et al., 2016). Corrections from regional or global network may be estimated and then applied to single-frequency receivers. An example for the global ionosphere corrections is the Global Ionosphere Maps (GIMs) produced by the International GNSS service (IGS). Another option to correct for the ionosphere delay for single-frequency receivers in real-time is to broadcast ionosphere corrections from Space Based Augmentation Systems (SBAS) (ArbesserRastburg, 2002; Hofmann-Wellenhof et al., 2008).

The second technique to account for ionosphere delay is to form ionosphere-free linear combination using both code and carrier phase observations on L1 from the single-frequency receiver. This technique is based on the Group and Phase Ionosphere Calibration (GRAPHIC) (Cai et al., 2013; Schüler et al., 2011; Shi et al., 2012; Sterle et al., 2015).

Since the availability of low-cost single-frequency receivers, several attempts have been carried out to reduce the cost and increase the accuracy which can be obtained from such 
receivers compared with geodetic grade receivers. Highsensitivity low-cost receivers have thousands of correlators to reduce the search space of each correlator and are able to acquire signals with low decibel watt (dBW) (Schwieger, 2007). Hedgecock et al. (2013) introduced the standalone relative localization system using low-cost single-frequency receivers. They found that tracking the relative motion of the neighboring nodes is an order of magnitude better than taking the difference between the absolute coordinates of each node. Ambiguity resolution, on the other hand, is not possible from single epoch data from single-frequency receivers(Odijk et al., 2012). However, ambiguity resolution can be achieved using less than 10 minutes of accumulated data, by which sub-cm and a few $\mathrm{cm}$ levels can be achieved for horizontal and vertical directions, respectively (Odijk et al., 2014). The performance of low-cost single-frequency receivers can be improved by using a geodetic grade antenna instead of the low-cost single-frequency antenna (Takasu and Yasuda, 2008).

Low-cost single-frequency receivers have been used in numerous applications. An unmanned aerial vehicle (UAV) can be occupied by low-cost single frequency receivers, which are controlled through radio communication control. The system works in RTK mode and gets corrections from at least one reference receiver (Stempfhuber and Buchholz, 2011). Lowcost single-frequency receivers can be used along with SBAS corrections for autonomous guidance of agricultural tractors. The pass-to-pass error in trajectories is within $1 \mathrm{~m}$ (AlonsoGarcia et al., 2011). It can be used in Structure Health Monitoring (SHM) applications such as monitoring the displacement. Averaging measurements from several GPS receivers can significantly reduce the noise level and the dynamic displacement response can be captured at $0.25 \mathrm{~m}$ amplitude (Jo et al., 2013). Low-cost single-frequency receivers can be used also to monitor the snow liquid water content and avalanche prediction by measuring the changes of GPS L1 carrier strength (signal-to-noise ratio) (Koch et al., 2014).

In this paper, u-blox NEO-7P low-cost single-frequency GPS receiver, which fulfills accuracy requirements for all RTK surveying applications (Sioulis et al., 2015), is used to collect GPS data using a hydrographic vessel. The main objective of the paper is to evaluate the performance of such singlefrequency receiver in hydrographic surveying applications.

\section{IHO POSITIONING STANDARDS}

The International Hydrographic Organization (IHO) published several standards that provide the minimum standards for hydrographic surveys execution to collect data to be used to compile navigational charts. Such standards must be achieved to assure both surface navigation safety and marine environment protection (IHO, 2008). According to the water depth, the IHO classifies surveys into four orders, namely; special order, order $1 \mathrm{a}$, order $1 \mathrm{~b}$, and order 2 . The first order is the special order which is the most rigorous among all hydrographic surveys orders. It is used for areas where under-keel clearance is critical and where bottom characteristics are potentially hazardous to vessels such as critical navigation channels, harbors, and berthing areas (generally depth less than $40 \mathrm{~m}$ ). the second order is order 1a which is for areas of depth more than $40 \mathrm{~m}$ and less than $100 \mathrm{~m}$ where under-keel clearance is less critical but man-made or natural features on the seabed are of concern to surface shipping may exist. Such areas like harbors, harbors approaching channels, and recommended tracks. The third order is order $1 \mathrm{~b}$, which is for areas of depth less than $100 \mathrm{~m}$ where under-keel clearance is not considered to be an issue for surface shipping in such areas. The fourth order is order 2, which is for areas deeper than $100 \mathrm{~m}$ where the general description of the sea floor is considered adequate and the man-made or natural features on the seabed will not have any impact on the surface navigation.

\subsection{Total Horizontal Uncertainty (THU)}

Hydrographic surveys measurements are affected by different sources of uncertainties, including random and systematic errors. All sources of measurement uncertainties are propagated, and the uncertainties of the computed parameters are then calculated, which is known as Total Propagated Uncertainty (TPU). The component of TPU in the horizontal plane is known as the Total Horizontal Uncertainty (THU), which is a 2 Dimensional (2D) quantity expressing latitude and longitude errors.

\subsection{Total Vertical Uncertainty (TVU)}

It is a 1 Dimensional (1D) quantity that expresses the component of the TPU in the vertical dimension. The depth uncertainty is affected by two errors, depth dependent and depth independent errors. The TVU can be computed at $95 \%$ confidence level as follows (IHO, 2008):

$$
T V U= \pm \sqrt{a^{2}+(b \times d)^{2}}
$$

where $\quad a=$ the depth independent portion of uncertainty

$\mathrm{b}=$ the coefficient that represents the depth dependent portion of uncertainty $\mathrm{d}=$ the depth

Table 1 summarizes the minimum standards for hydro-graphic surveys orders.

\section{FIELD TEST}

To test the performance of low-cost single-frequency GPS receivers in hydrographic surveying, raw GPS data was collected using New-7P u-blox GPS receiver. The test area was Sharm Obhur, Jeddah, Saudi Arabia where Faculty of Maritime Studies (FMS) is located. The base station was setup on the rooftop of FMS building using Ashtech ProFlex 500 GNSS receiver and the corresponding measurements simultaneously collected and employed to estimate the Real-Time Kinematic (RTK) solution, which considered as the reference solution. The length of the collected data was about 2.0 hours using King Abdulaziz University (KAU) vessel Hydrography 1, Figure 1. Figure 2, on the other hand, shows the trajectory of the data collected in November, 2015. 


\begin{tabular}{|c|c|c|c|c|}
\hline \multirow{2}{*}{ Table Head } & \multicolumn{4}{|c|}{ Hydrographic Surveys Order } \\
\hline & Special Order & Order 1a & Order $1 b$ & Order 2 \\
\hline Depth (d) & $<40 \mathrm{~m}$ & $<100 \mathrm{~m}$ & $<100 \mathrm{~m}$ & $>100 \mathrm{~m}$ \\
\hline $\begin{array}{c}\text { Area } \\
\text { Characteristics }\end{array}$ & $\begin{array}{l}\text { Harbors, berthing areas, } \\
\text { and associated critical } \\
\text { channels with minimum } \\
\text { under-keel clearances }\end{array}$ & $\begin{array}{l}\text { Under-keel clearance } \\
\text { is less critical but } \\
\text { features of concern to } \\
\text { surface shipping may } \\
\text { exist }\end{array}$ & $\begin{array}{l}\text { Under-keel clearance is } \\
\text { not an issue for surface } \\
\text { shipping expected to } \\
\text { transit the area }\end{array}$ & $\begin{array}{c}\text { general description or } \\
\text { the sea floor is } \\
\text { considered adequate }\end{array}$ \\
\hline $\begin{array}{c}\text { Total Horizontal } \\
\text { Uncertainty (THU) }\end{array}$ & $2 \mathrm{~m}$ & $5 m+0.05 d$ & $5 m+0.05 d$ & $20 \mathrm{~m}+0.1 \mathrm{~d}$ \\
\hline $\begin{array}{c}\text { Total Vertical } \\
\text { Uncertainty (TVU) }\end{array}$ & $\begin{array}{l}\mathrm{a}=0.25 \mathrm{~m} \\
\mathrm{~b}=0.0075\end{array}$ & $\begin{array}{r}\mathrm{a}=0.5 \mathrm{~m} \\
\mathrm{~b}=0.013\end{array}$ & $\begin{aligned} \mathrm{a} & =0.5 \mathrm{~m} \\
\mathrm{~b} & =0.013\end{aligned}$ & $\begin{array}{r}\mathrm{a}=1.0 \mathrm{~m} \\
\mathrm{~b}=0.023\end{array}$ \\
\hline
\end{tabular}

Table 1. IHO Minimum Standards for Hydeographic Surveys (IHO, 2008)

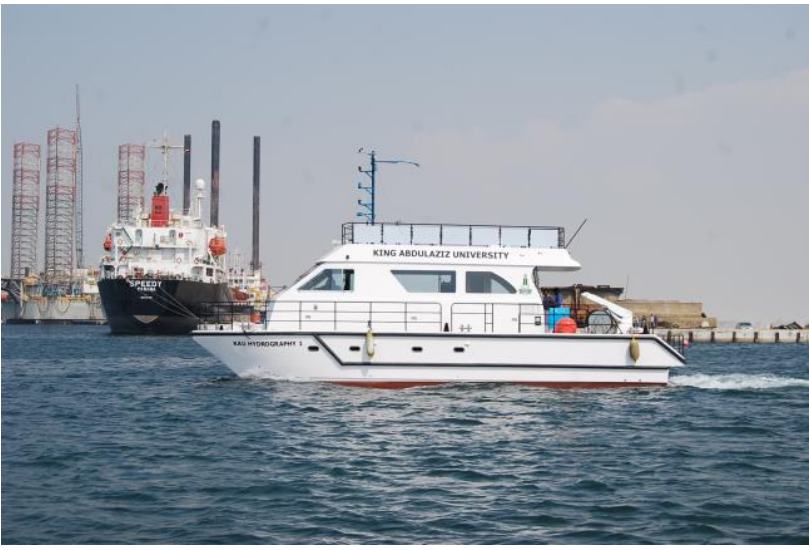

Figure 1. KAU Hydrography 1 Vessel

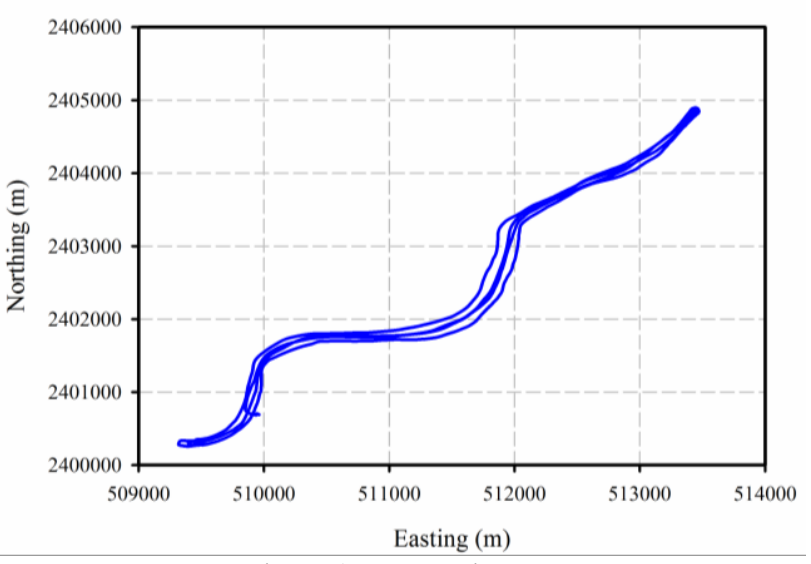

Figure 2. Test Trajectory

\section{RESULTS AND DISCUSSION}

The real-time solution from New-7P low-cost single-frequency GPS receiver is recorded during the surveying session at $1 \mathrm{~Hz}$ sampling frequency. Moreover, the reference solution from Hydrography 1 vessel is recorded in real-time at the same sampling rate. The single-frequency solution is compared to the reference solution to investigate whether the low-cost singlefrequency receivers satisfy $\mathrm{IHO}$ hydrographic surveys minimum standards according to Table 1 . Both THU and TVU of the low- cost single-frequency receiver are computed at $39 \%$ confidence level then transformed to $95 \%$ confidence level as follows (Mohamed El-Diasty and Elsobeiey, 2015):

$$
\begin{gathered}
T H U_{39 \%}^{2 D}=\sqrt{\frac{\sum_{i=1}^{n}\left(\hat{N}_{R}-\hat{N}_{S F S}\right)_{i}^{2}+\left(\hat{E}_{R}-\hat{E}_{S F S}\right)_{i}^{2}}{n}} \\
T H U_{95 \%}^{2 D}=2.44 T H U_{39 \%}^{2 D} \\
T V U_{39 \%}^{1 D}=\sqrt{\frac{\sum_{i=1}^{n}\left(\hat{U}_{R}-\hat{U}_{S F S}\right)_{i}^{2}}{n}} \\
T V U_{95 \%}^{1 D}=1.96 T V U_{39 \%}^{1 D}
\end{gathered}
$$

Where $T H U_{39 \%}^{2 D}=$ the total $2 \mathrm{D}$ horizontal uncertainty of Northing and Easting position error at 39\% confidence level

$\hat{N}_{R}=$ the easting coordinate of the reference solution (the vessel integrated solution), $\hat{N}_{S F S}$ is the Northing single-frequency position

$\hat{E}_{R}=$ the Easting coordinate of the reference solution

$\hat{E}_{S F S}=$ the Easting single-frequency position

$\mathrm{n}$ is the total number of epochs

$T H U_{95 \%}^{2 D}=$ the $2 \mathrm{D}$ total horizontal uncertainty of Northing and Easting position error at 95\% confidence level

$T V U_{39 \%}^{1 D}=$ the total $1 \mathrm{D}$ vertical uncertainty of the Up component at $39 \%$ confidence level

$T V U_{95 \%}^{1 D}=$ the total $1 \mathrm{D}$ vertical uncertainty of the $\mathrm{Up}$ component at $95 \%$ confidence level

Figure 3 shows the Easting, Northing and the 2D horizontal error of the single-frequency solution compared with the reference solution. In addition, Figure 4 shows the 2D 
horizontal error and the 1D vertical error. Figures 3 and 4 show that the maximum absolute 2D horizontal and 1D vertical errors are about $3.12 \mathrm{~m}$ and 3.69 , respectively. however, the mean error is about $1.26 \mathrm{~m}$ and $-0.62 \mathrm{~m}$ for both $2 \mathrm{D}$ horizontal error and $1 \mathrm{D}$ vertical error, respectively. Moreover, Table2 summarizes the THU and TVU values at $39 \%$ and $95 \%$ confidence levels.

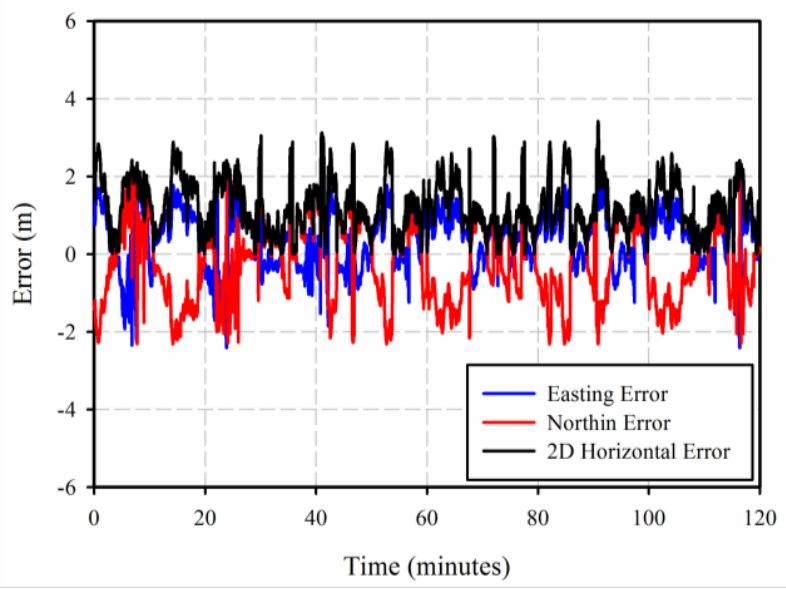

Figure 3. Northing, Easting, and the 2D horizontal Errors of Low-cost Single-frequency Receiver

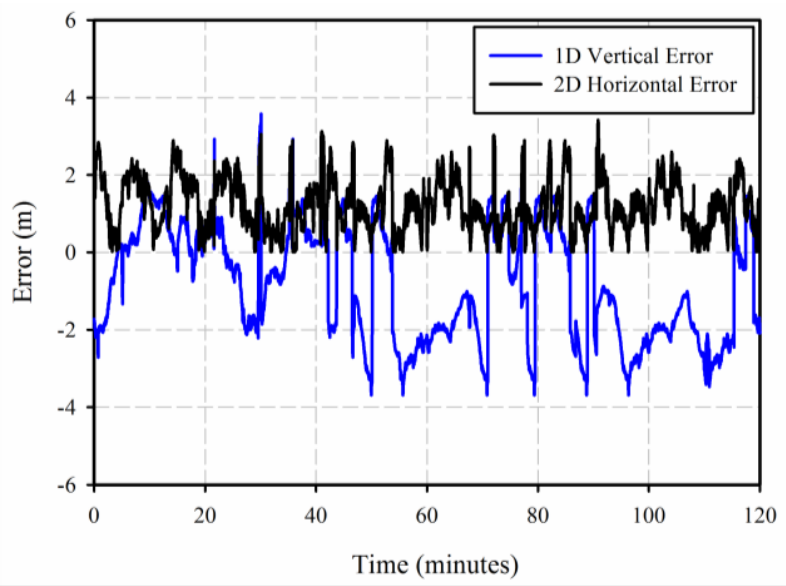

Figure 4. 2D horizontal Errors and 1D Vertical Errors of Lowcost Single-frequency Receiver

\begin{tabular}{cc}
\hline Error Parameter & Low-cost Single-frequency Solution \\
\hline$T H U_{39 \%}^{2 D}$ & 0.692 \\
\hline$T H U_{95 \%}^{2 D}$ & $2.44 \times T H U_{39 \%}^{2 D}=1.690$ \\
\hline$T V U_{39 \%}^{1 D}$ & 1.282 \\
\hline$T V U_{95 \%}^{1 D}$ & $1.96 \times T V U_{39 \%}^{1 D}=2.512$ \\
\hline
\end{tabular}

Table 2. Summary Statistics of the Low-cost Single-frequency Solution

Our analysis showed that the THU is $1.69 \mathrm{~m}$ at $95 \%$ confidence level which meets all hydrographic surveys types according to the IHO standards (Table 1) at any depth. However, the TVU is $2.512 \mathrm{~m}$ at the same confidence level, which only meets hydrographic surveys order 2 at $100 \mathrm{~m}$ depth.

\section{CONCLUSIONS}

This paper investigates the performance of real-time precise point positioning with low-cost single-frequency GPS receivers in hydrographic surveying applications. A session of two hours length is used to collect single-frequency data using King Abduaziz University vessel, Hydrography 1 . The vessel solution, which consists of the RTK integrated solution is used as a reference for comparison. To check if the single-frequency receivers fulfil the IHO requirements, both THU and TVU are estimated at $95 \%$ confidence level. It is shown that the total horizontal uncertainty from the solution of low-cost singlefrequency receivers is about $1.69 \mathrm{~m}$, which meet the IHO standards for all hydrographic surveys orders at any depth (special order, order $1 \mathrm{a}$, order $1 \mathrm{~b}$, and order 2 ). However, the total vertical uncertainty from the solution of single-frequency receivers is found to be $2.512 \mathrm{~m}$, which meets only order 2 requirements for vertical accuracy at depth more than or equal $100 \mathrm{~m}$. in fact, ublox single-frequency GPS receivers accounting for troposphere and ionosphere errors by applying the corrections transmitted from SBAS. Such corrections are limited to an accuracy of about $0.2 \mathrm{~m}$, which affects the receiver solution, especially the height component. So, further investigations are required to improve the height component of single-frequency receivers in real-time solution, especially tropospheric delay, which highly correlated with ellipsoidal height.

\section{ACKNOWLEDGMENTS}

The data set used in this research was collected using King Abdulaziz University vessel, Hydrography 1. The Author, therefore, acknowledges with thanks the technical stuff from hydrographic surveying department, Faculty of Maritime Studies.

\section{REFERENCES}

Alonso-Garcia, S., Gomez-Gil, J., Arribas, J., 2011. Evaluation of the use of low-cost GPS receivers in the autonomous guidance of agricultural tractors. Spanish Journal of Agricultural Research 9, 377-388.

Arbesser-Rastburg, B., 2002. Ionospheric corrections for satellite navigation using EGNOS. Proc. of XXVII-th URSI General Assembly, Maastricht.

Cai, C., Liu, Z., Luo, X., 2013. Single-frequency Ionospherefree Precise Point Positioning Using Combined GPS and GLONASS Observations. The Journal of Navigation 66, 417434.

El-Rabbany, A., 2006. Introduction to GPS : the Global Positioning System, 2nd ed. Artech House, Boston, MA.

Hedgecock, W., Maroti, M., Sallai, J., Volgyesi, P., Ledeczi, A., 2013. High-accuracy differential tracking of low-cost GPS receivers, Proceeding of the 11th annual international conference on Mobile systems, applications, and services. ACM, pp. 221-234. 
Hofmann-Wellenhof, B., Lichtenegger, H., Wasle, E., 2008. GNSS - global navigation satellite systems : GPS, GLONASS, Galileo, and more. Springer, Wien ; New York.

IHO, 2008. IHO STANDARDS FOR HYDROGRAPHIC SURVEYS, Special Publication No. 44, 5th Edition, February 2008, International Hydrographic Bureau, MONACO. http://www.iho.int/iho_pubs/standards/S-44_5E.pdf.

Jo, H., Sim, S.-H., Tatkowski, A., Spencer, B.F., Nelson, M.E., 2013. Feasibility of displacement monitoring using low-cost GPS receivers. Structural Control and Health Monitoring 20, 1240-1254.

Koch, F., Prasch, M., Schmid, L., Schweizer, J., Mauser, W., 2014. Measuring Snow Liquid Water Content with Low-Cost GPS Receivers. Sensors 14, 20975-20999.

Mohamed El-Diasty, Elsobeiey, M., 2015. Precise Point Positioning Technique with IGS Real-Time Service (RTS) for Maritime Applications. Positioning 6, 71-80.

Odijk, D., Teunissen, P., Zhang, B., 2012. Single-Frequency Integer Ambiguity Resolution Enabled GPS Precise Point Positioning. Journal of Surveying Engineering 138, 193-202.

Odijk, D., Teunissen, P.G., Khodabandeh, A., 2014. SingleFrequency PPP-RTK: Theory and Experimental Results, in: Rizos, C., Willis, P. (Eds.), Earth on the Edge: Science for a Sustainable Planet. Springer Berlin Heidelberg, pp. 571-578.

Schüler, T., Diessongo, H., Poku-Gyamfi, Y., 2011. Precise ionosphere-free single-frequency GNSS positioning. GPS Solut $15,139-147$.

Schwieger, V., 2007. High-Sensitivity GPS-the low cost future of GNSS. FIG Working Week, Hong Kong, SAR 13, 2007.

Shi, C., Gu, S., Lou, Y., Ge, M., 2012. An improved approach to model ionospheric delays for single-frequency Precise Point Positioning. Advances in Space Research 49, 1698-1708.

Sioulis, A., Tsakiri, M., Stathas, D., 2015. Evaluation of low cost, high sensitivity GNSS receivers based on the ISO RTK standards. INTERNATIONAL JOURNAL OF GEOMATICS AND GEOSCIENCES 6, pp 1597- 1606

Stempfhuber, W., Buchholz, M., 2011. A precise, low-cost RTK GNSS system for UAV applications. International Archives of Photogrammetry, Remote Sensing and Spatial Information Science 38, 1-C22.

Sterle, O., Stopar, B., Pavlovčič Prešeren, P., 2015. Singlefrequency precise point positioning: an analytical approach. J Geod 89, 793-810.

Takasu, T., Yasuda, A., 2008. Evaluation of RTK-GPS performance with low-cost single-frequency GPS receivers, Proceedings of international symposium on GPS/GNSS 2008 Tokyo, Japan, pp 852-861, pp. 852-861.

Wang, N., Yuan, Y., Li, Z., Huo, X., 2016. Improvement of Klobuchar model for GNSS single-frequency ionospheric delay corrections. Advances in Space Research. 